\title{
The Repertoire of Transfer RNA Genes Is Tuned to Codon Usage Bias in the Genomes of Phytophthora sojae and Phytophthora ramorum
}

\author{
Sucheta Tripathy, and Brett M. Tyler \\ Virginia Bioinformatics Institute, Virginia Polytechnic Institute and State University, Blacksburg, VA 24061, U.S.A. \\ Submitted 11 April 2006. Accepted 7 August 2006.
}

In all, 238 and 155 transfer (t)RNA genes were predicted from the genomes of Phytophthora sojae and $P$. ramorum, respectively. After omitting pseudogenes and undetermined types of tRNA genes, there remained $208 P$. sojae tRNA genes and $140 P$. ramorum tRNA genes. There were 45 types of tRNA genes, with distinct anticodons, in each species. Fourteen common anticodon types of tRNAs are missing altogether from the genome in the two species; however, these appear to be compensated by wobbling of other tRNA anticodons in a manner which is tied to the codon bias in Phytophthora genes. The most abundant tRNA class was arginine in both $P$. sojae and $P$. ramorum. A codon usage table was generated for these two organisms from a total of $9,803,525$ codons in $P$. sojae and 7,496,598 codons in $P$. ramorum. The most abundant codon type detected from the codon usage tables was GAG (encoding glutamic acid), whereas the most numerous tRNA gene had a methionine anticodon (CAT). The correlation between the frequencies of tRNA genes and the codon frequencies in protein-coding genes was very low $(0.12$ in $P$. sojae and 0.19 in $P$. ramorum); however, the correlation between amino acid tRNA gene frequency and the corresponding amino acid codon frequency in $P$. sojae and $P$. ramorum was substantially higher (0.53 in $P$. sojae and 0.77 in $P$. ramorum). The codon usage frequencies of $P$. sojae and $P$. ramorum were very strongly correlated $(0.99)$, as were tRNA gene frequencies (0.77). Approximately $60 \%$ of orthologous tRNA gene pairs in $P$. sojae and $P$. ramorum are located in regions that have conserved synteny in the two species.

Additional keywords: tRNA gene copy number.

Codon usage bias, defined as the unequal usage of synonymous codons for encoding amino acids, first was described by Grantham and colleagues (Grantham et al. 1981). The possibility of relationships among synonymous codon usage, transfer (t)RNA availability, and the rate of protein synthesis was studied even earlier (Zuckerkandl and Pauling 1965).

Codon usage bias has been found in many organisms, both prokaryotic and eukaryotic. This bias varies considerably among organisms and even within genes of the same organism. In several different species, codon usage bias was found to be

Corresponding author: S. Tripathy; Telephone: +1540231 8138; Fax: +1 540231 2606; E-mail: sutripa @ vbi.vt.edu

The $\boldsymbol{e}$-Xtra logo stands for "electronic extra" and indicates the HTML abstract available on-line contains supplemental material not included in the print edition. An additional table appears on-line. correlated weakly with gene expression level. Previous codon usage analyses showed associations with various biological factors, such as gene expression level (Bulmer 1987; EyreWalker 1996), gene length (Wan et al. 2003), gene translation initiation signal (Ma et al. 2002), protein amino acid composition (D'Onofrio et al. 1991; Lobry and Gautier 1994), and tRNA abundance (Bulmer 1987; Ikemura 1982; Kanaya et al. 1999). A major driving force responsible for deviations from a neutral choice of codons is translational selection, which results in adjustment of codon usage to the abundance of the various tRNA species. Whole-genome analysis in the yeast Saccharomyces cerevisiae revealed that codon usage and protein amino acid composition were adapted to both gene copy number and intracellular content of individual tRNA species (Percudani et al. 1997). Although the biased usage of synonymous codons is, to a large extent, explained by this mutual relationship, the preference for one codon over another also may depend on more intrinsic aspects of the translational machinery. One such aspect is the stability of the codon-anticodon interaction. The contribution of codon-anticodon complex stability to translational selection can be evaluated by measuring the relative usage of cognate codons (i.e., codons read by a single tRNA species), whose choice is independent of tRNA abundance (Percudani and Ottonello 1999).

Most of the work on codon usage bias has been focused on the analysis of codon frequencies from the DNA sequences of protein-coding genes. A complementary approach is to examine the distribution of tRNA gene number and anticodon type. With the completion of the draft genome sequences of the oomycete pathogens Phytophthora sojae and P. ramorum, we have had the opportunity to study the complete tRNA gene sets from these two pathogens and to assess the relationship of tRNA gene distribution with codon usage. In this study, we present complete codon usage tables for these two organisms along with evidence, based on tRNA gene copy numbers, suggesting that selection acts on codon usage bias and on the tRNA gene repertoire in the Phytophthora genomes.

\section{RESULTS AND DISCUSSION}

We performed a genomewide analysis of tRNA gene distribution for $P$. sojae and $P$. ramorum to understand codon bias as well as the relative frequencies of tRNA genes in these organisms. In all, 238 tRNA genes were predicted in $P$. sojae and 155 tRNA genes were predicted in $P$. ramorum. Of the 238 predicted genes in $P$. sojae, 16 were pseudo-tRNA genes (without any detectable secondary structure) and 14 were predicted tRNA genes of undetermined type. In P. ramorum, of the 155 predicted genes, 11 were pseudogenes and 4 were of undetermined type. 


\section{Isoaccepting tRNA types.}

The various types of tRNAs carrying a specific type of amino acid are called isoaccepting tRNAs. Gene copy numbers vary greatly among isoaccepting tRNAs. For both $P$. sojae and $P$. ramorum, all 20 isoaccepting tRNA classes were found, representing 47 tRNA genes. Cysteine tRNA genes were missing from the $P$. sojae sequence assembly and tryptophan tRNA genes were missing from the $P$. ramorum assembly. However, when the trace archives were searched, three cysteine genes were found in $P$. sojae, and one tryptophan tRNA gene in $P$. ramorum. The highest tRNA gene copy number found in both the species was for arginine, whereas the most numerous singlecodon-type tRNA gene was methionine.

\section{Codon preference.}

Codon usage for $P$. sojae and $P$. ramorum is illustrated in Table 1. The correlation between the codon usage frequencies of $P$. sojae and $P$. ramorum was highly significant $(r=0.99)$ (Fig. 1).

Phytophthora spp. show strong codon usage bias. As has been noted previously (Jiang and Govers 2006; Randall et al. 2005), codon usage in Phytophthora spp. is biased heavily toward use of $\mathrm{G}$ and $\mathrm{C}$ in the third position, with the exception that GGG is used relatively rarely. Also, $\mathrm{T}$ is preferred over A in the third position. The most frequent codon for both organisms is GAG coding for glutamic acid. Unlike many other higher organisms where Asp codons do not exhibit codon usage bias (Moriyama and Powel 1997), Phytophthora Asp codons are strongly biased toward GAC over GAT. The least frequent codon in the two species is ATA, which codes for isoleucine.

In addition to the third base bias toward $\mathrm{G}$ or $\mathrm{C}$, the presence of $\mathrm{G}, \mathrm{C}$, or both in the first two positions also is slightly more favored in both $P$. sojae and $P$. ramorum $(27$ and $26 \%$, respectively, of total codon frequency) over the presence of $\mathrm{A}$, $\mathrm{T}$, or both in the first two places (20 and $22 \%$, respectively, of total codon frequency). This observation is similar to earlier observation that GC-rich genomes tend to favor GC-rich codons over AT-rich codons (Knight et al. 2001).

\section{Absence of specific anticodon tRNA types is tuned to the codon usage bias.}

There are a total of 208 confirmed tRNA genes in $P$. sojae and 140 tRNA genes in $P$. ramorum. The confirmed tRNA genes present in each organism represent 45 different tRNA gene anticodons. However, 16 anticodons were missing from the $P$. sojae and $P$. ramorum tRNA gene repertoires, of which 14 anticodons were missing from both (Table 2, in bold). Seven of the missing anticodon types (GGC, GCG, GAG, GGG, GGA, CGU, and GAC) (Table 2, square brackets) correspond to codons with a high relative frequency of usage $(0.034,0.026,0.023,0.013,0.013,0.026$, and 0.02 in $P$. sojae and $0.021,0.018,0.017,0.008,0.01,0.02$, and 0.014 in $P$. ramorum).

The explanation for the missing tRNA classes appears to be related to functional redundancy among tRNA genes. Many tRNAs can pair with more than one codon as a result of wobble pairing (usually, G-U pairing) and modifications of anticodon bases (usually, deamination of A to form inosine, which can pair with all four bases). In the presence of functional redundancy, nonessential tRNA genes or their corresponding amino-acyl tRNA synthetases may be lost due to mutation. In the case of the two Phytophthora spp., the loss of the tRNA genes appears to be constrained by the codon usage bias toward $\mathrm{C}$ and $\mathrm{G}$ in the third position.

In every case but one in which an amino acid is encoded by a codon with $\mathrm{C}$ or $\mathrm{U}$ in the third position, including the serine codons AGC and AGU, the tRNA class corresponding to $\mathrm{U}$ in the third position is missing. Therefore, for these amino acids, only tRNAs with $G$ in the first position of the anticodon are available to decode both NNC and NNU codons. Because the G-C pairing is more stable than the G-U wobble pairing, these tRNAs presumably bind more efficiently to the NNC codons. There is a strong bias toward use of NNC codons over NNU codons; therefore, the loss of the ANN tRNA genes presumably has conferred no selective disadvantage. The only exception is phenylalanine tRNAs in which both GAA and AAA anticodons are present.

In the case of amino acids in which there are three or four possible bases in the third position, including serine UCN codons, leucine CUN codons, and arginine CGN codons, in all but one instance (glycine), tRNAs with GNN anticodons are missing. Presumably, therefore, the NNC specificity is provided, with no selective disadvantage, by tRNAs with ANN anticodons that are converted to INN. Inosine has the ability to pair with all four of the conventional bases; however, the stability of pairing is substantially higher for the pairing with $\mathrm{C}$ than with any of the other bases and poorest for the pairing with $G$ (Watkins and SantaLucia 2005). Therefore, tRNAs with INN anticodons will efficiently translate NNC codons, resulting in the eventual loss of tRNAs with GNN anticodons. On the other hand, the poor pairing of INN with NNG codons combined with the high abundance of NNG codons presumably has prevented the loss of CNN tRNAs dedicated to decoding NNG codons. The efficiency of pairing of INN anticodons with NNA codons also appears to be sufficiently poor that tRNA genes with UNN anticodons have been retained, despite the fact that NNA codons are the least frequent.

For amino acids encoded by codons with purines in the third position, including leucine UUR codons and arginine AGR codons, there is no case in which a codon specificity is missing. $\mathrm{G}$ can base pair with $\mathrm{U}$; therefore, in principle, tRNAs with UNN anticodons could decode both NNG and NNA codons. However, in that case, the more stable pairing of A to $\mathrm{U}$ over $\mathrm{G}$ to $\mathrm{U}$ would favor pairing with the least common base found at the third position in Phytophthora codons, A, over pairing with the more common $\mathrm{G}$. This presumably has created selection for the retention of tRNA genes with CNN anticodons. Therefore, the consistent presence of tRNAs with CNN anticodons specialized for decoding NNG codons supports the hypothesis that the presence and absence of tRNA specificities in the Phytophthora genomes is tuned to the strong bias toward $\mathrm{G}$ and $\mathrm{C}$ in the third codon position, as a result of selection pressure to retain only those tRNA genes that are essential for efficiently translating the most common codons.

Together, these observations reveal that, in these two Phytophthora spp., extensive use of adenosine to inosine conversion in the $5^{\prime}$ end of the tRNA anticodon and wobble pairing has resulted in a streamlined repertoire of tRNA genes tightly tuned to the third codon position preference for $\mathrm{G}$ and $\mathrm{C}$.

\section{Correlation between codon frequency and tRNA gene copy number.}

In both species, the most abundant class of tRNA gene, by amino acid specificity, was the arginine-tRNA genes. There are 30 arginine tRNA genes in $P$. sojae and 17 in $P$. ramorum. The next most abundant tRNA genes in both species were leucine tRNA genes. The most abundant tRNA gene in both species, by anticodon sequence, was the methionine tRNA gene. In contrast, the most frequently used single codon in the genomes was GAG coding for glutamic acid (46.685 of 1,000 in P. sojae and 46.103 of 1,000 in $P$. ramorum). There was a positive correlation between the number of tRNA genes for each amino 
Table 1. Codon usage table in Phytophthora sojae and P. ramorum calculated after predicting 9,803,525 codons in P. sojae and 7,496,598 codons in $P$. ramorum from the coding region

\begin{tabular}{|c|c|c|c|c|c|c|c|c|c|}
\hline \multirow[b]{3}{*}{ Codon } & \multirow[b]{3}{*}{ Amino acid } & \multicolumn{4}{|c|}{ P. sojae } & \multicolumn{4}{|c|}{ P. ramorum } \\
\hline & & \multirow[b]{2}{*}{ Freq. $^{a}$} & \multicolumn{2}{|c|}{ Number per 1,000 } & \multirow[b]{2}{*}{ Total $^{\text {d }}$} & \multirow[b]{2}{*}{ Freq. $^{\mathrm{a}}$} & \multicolumn{2}{|c|}{ Number per 1,000 } & \multirow[b]{2}{*}{ Total $^{\mathbf{d}}$} \\
\hline & & & Codons $^{\mathrm{b}}$ & Amino acids ${ }^{c}$ & & & Codons $^{b}$ & Amino $\operatorname{acids}^{\mathbf{c}}$ & \\
\hline GCT & Ala & 0.212 & 20.915 & 98.79 & 204,274 & 0.221 & 20.796 & 93.877 & 155,555 \\
\hline GCG & Ala & 0.338 & 33.357 & $\ldots$ & 325,793 & 0.316 & 29.775 & $\ldots$ & 222,713 \\
\hline GCA & Ala & 0.147 & 14.501 & $\ldots$ & 141,628 & 0.17 & 16.008 & $\ldots$ & 119,741 \\
\hline GCC & Ala & 0.304 & 30.017 & $\ldots$ & 293,168 & 0.292 & 27.516 & $\ldots$ & 205,816 \\
\hline CGT & Arg & 0.152 & 10.985 & 72.324 & 107,296 & 0.177 & 11.056 & 62.249 & 82,700 \\
\hline CGG & Arg & 0.162 & 11.683 & $\ldots$ & 114,111 & 0.147 & 9.147 & $\ldots$ & 68,423 \\
\hline AGG & Arg & 0.092 & 6.642 & $\ldots$ & 64,874 & 0.072 & 4.467 & $\ldots$ & 33,415 \\
\hline CGA & Arg & 0.158 & 11.437 & $\ldots$ & 111,706 & 0.16 & 9.989 & $\ldots$ & 74,719 \\
\hline AGA & Arg & 0.073 & 5.273 & $\ldots$ & 51,509 & 0.066 & 4.087 & $\ldots$ & 30,573 \\
\hline CGC & Arg & 0.364 & 26.304 & $\ldots$ & 256,906 & 0.379 & 23.645 & $\ldots$ & 176,866 \\
\hline AAC & Asn & 0.78 & 24.225 & 31.039 & 236,597 & 0.749 & 24.858 & 33.113 & 185,934 \\
\hline AAT & Asn & 0.22 & 6.814 & $\ldots$ & 66,554 & 0.251 & 8.332 & $\ldots$ & 62,326 \\
\hline GAC & Asp & 0.733 & 41.224 & 56.236 & 402,626 & 0.701 & 40.595 & 57.764 & 303,647 \\
\hline GAT & Asp & 0.267 & 15.012 & $\ldots$ & 146,618 & 0.299 & 17.303 & $\ldots$ & 129,424 \\
\hline TGT & Cys & 0.27 & 4.691 & 17.348 & 45,822 & 0.276 & 4.399 & 15.913 & 32,905 \\
\hline TGC & Cys & 0.73 & 12.657 & $\ldots$ & 123,623 & 0.724 & 11.551 & & 86,402 \\
\hline CAG & Gln & 0.708 & 29.161 & 41.189 & 284,809 & 0.706 & 29.647 & 41.882 & 221,757 \\
\hline CAA & Gln & 0.292 & 12.028 & $\ldots$ & 117,481 & 0.294 & 12.332 & $\ldots$ & 92,244 \\
\hline GAG & Glu & 0.724 & 46.685 & 64.487 & 455,963 & 0.694 & 46.103 & 66.265 & 344,849 \\
\hline GAA & Glu & 0.276 & 17.802 & $\ldots$ & 173,870 & 0.306 & 20.314 & $\ldots$ & 151,951 \\
\hline GGG & Gly & 0.165 & 10.576 & 63.927 & 103,292 & 0.148 & 9.431 & 63.615 & 70,548 \\
\hline GGC & Gly & 0.459 & 29.37 & $\ldots$ & 286,848 & 0.445 & 28.389 & $\ldots$ & 212,350 \\
\hline GGA & Gly & 0.201 & 12.833 & $\ldots$ & 125,339 & 0.201 & 12.786 & $\ldots$ & 95,640 \\
\hline GGT & Gly & 0.174 & 11.148 & $\ldots$ & 108,881 & 0.206 & 13.154 & $\ldots$ & 98,392 \\
\hline CAC & His & 0.746 & 17.615 & 23.6 & 172,044 & 0.749 & 17.281 & 23.01 & 129,261 \\
\hline CAT & His & 0.254 & 5.985 & $\ldots$ & 58,456 & 0.251 & 5.782 & $\ldots$ & 43,254 \\
\hline ATT & Ile & 0.261 & 9.264 & 35.451 & 90,481 & 0.311 & 11.868 & 38.051 & 88,775 \\
\hline ATA & Ile & 0.054 & 1.9 & $\ldots$ & 18,589 & 0.047 & 1.811 & $\ldots$ & 13,550 \\
\hline ATC & Ile & 0.685 & 24.287 & $\ldots$ & 237,203 & 0.641 & 24.46 & $\ldots$ & 182,958 \\
\hline CTT & Leu & 0.1 & 8.927 & 89.104 & 87,192 & 0.11 & 10.211 & 92.294 & 76,378 \\
\hline TTG & Leu & 0.148 & 13.149 & $\ldots$ & 128,428 & 0.165 & 15.292 & $\ldots$ & 114,384 \\
\hline TTA & Leu & 0.025 & 2.194 & $\ldots$ & 21,429 & 0.026 & 2.425 & $\ldots$ & 18,139 \\
\hline CTA & Leu & 0.058 & 5.166 & $\ldots$ & 50,464 & 0.061 & 5.599 & $\ldots$ & 41,882 \\
\hline CTC & Leu & 0.261 & 23.248 & $\ldots$ & 227,055 & 0.245 & 22.649 & $\ldots$ & 169,413 \\
\hline CTG & Leu & 0.409 & 36.42 & $\ldots$ & 355,707 & 0.393 & 36.332 & $\ldots$ & 271,762 \\
\hline AAG & Lys & 0.838 & 40.265 & 48.046 & 393,254 & 0.794 & 39.727 & 49.922 & 297,153 \\
\hline AAA & Lys & 0.162 & 7.781 & & 75,998 & 0.206 & 10.311 & $\ldots$ & 77,126 \\
\hline ATG & Met & 1 & 22.847 & 22.847 & 223,139 & 1 & 24.573 & 24.516 & 183,805 \\
\hline TTC & Phe & 0.787 & 26.895 & 34.182 & 262,682 & 0.732 & 27.224 & 37.108 & 203,635 \\
\hline TTT & Phe & 0.213 & 7.287 & $\ldots$ & 71,173 & 0.268 & 9.97 & $\ldots$ & 74,574 \\
\hline ССТ & Pro & 0.177 & 9.294 & 52.382 & 90,779 & 0.188 & 8.977 & 47.523 & 67,150 \\
\hline CCG & Pro & 0.398 & 20.829 & $\ldots$ & 203,433 & 0.391 & 18.618 & $\ldots$ & 139,262 \\
\hline CCA & Pro & 0.174 & 9.104 & $\ldots$ & 88,919 & 0.184 & 8.766 & $\ldots$ & 65,572 \\
\hline $\mathrm{CCC}$ & Pro & 0.251 & 13.155 & $\ldots$ & 128,487 & 0.237 & 11.27 & $\ldots$ & 84,303 \\
\hline TCT & Ser & 0.094 & 7.746 & 82.276 & 75,661 & 0.102 & 8.277 & 80.826 & 61,917 \\
\hline TCG & Ser & 0.292 & 24.027 & $\ldots$ & 234,665 & 0.287 & 23.251 & $\ldots$ & 173,915 \\
\hline AGC & Ser & 0.258 & 21.207 & $\ldots$ & 207,126 & 0.245 & 19.818 & $\ldots$ & 148,242 \\
\hline TCA & Ser & 0.085 & 6.952 & $\ldots$ & 67,904 & 0.088 & 7.134 & $\ldots$ & 53,362 \\
\hline TCC & Ser & 0.166 & 13.69 & $\ldots$ & 133,714 & 0.161 & 13.045 & $\ldots$ & 97,577 \\
\hline AGT & Ser & 0.105 & 8.654 & $\ldots$ & 84,527 & 0.117 & 9.48 & $\ldots$ & 70,951 \\
\hline ACT & Thr & 0.16 & 9.368 & 58.727 & 91,496 & 0.158 & 9.404 & 59.224 & 70,345 \\
\hline ACC & Thr & 0.261 & 15.334 & $\ldots$ & 149,770 & 0.246 & 14.579 & $\ldots$ & 109,053 \\
\hline ACA & Thr & 0.125 & 7.353 & $\ldots$ & 71,819 & 0.145 & 8.601 & $\ldots$ & 64,335 \\
\hline ACG & Thr & 0.454 & 26.672 & $\ldots$ & 260,505 & 0.451 & 26.776 & $\ldots$ & 200,284 \\
\hline TAC & Tyr & 0.81 & 20.064 & 24.765 & 195,959 & 0.794 & 20.647 & 25.934 & 154,439 \\
\hline TAT & Tyr & 0.19 & 4.701 & $\ldots$ & 45,915 & 0.206 & 5.347 & $\ldots$ & 39,999 \\
\hline TGG & Trp & 1 & 13.458 & 13.458 & 131,446 & 1 & 12.445 & 12.416 & 93,087 \\
\hline GTT & Val & 0.132 & 9.184 & 69.791 & 89,697 & 0.139 & 10.084 & 72.172 & 75,432 \\
\hline GTG & Val & 0.504 & 35.158 & $\ldots$ & 343,376 & 0.523 & 37.837 & $\ldots$ & 283,018 \\
\hline GTA & Val & 0.068 & 4.722 & $\ldots$ & 46,121 & 0.074 & 5.375 & $\ldots$ & 40,208 \\
\hline GTC & Val & 0.297 & 20.727 & $\ldots$ & 202,437 & 0.263 & 19.042 & $\ldots$ & 142,431 \\
\hline TAA & Stop & 0.225 & $\ldots$ & $\ldots$ & 8,282 & 0.297 & $\ldots$ & $\ldots$ & 4,983 \\
\hline TAG & Stop & 0.241 & $\ldots$ & $\ldots$ & 8,907 & 0.313 & $\ldots$ & $\ldots$ & 5,244 \\
\hline TGA & Stop & 0.534 & $\ldots$ & $\ldots$ & 19,698 & 0.39 & $\ldots$ & $\ldots$ & 6,550 \\
\hline
\end{tabular}

${ }^{\text {a }}$ Relative synonymous codon usage frequency.

${ }^{\mathrm{b}}$ Number of codons per 1,000 codons.

${ }^{\mathrm{c}}$ Sum of codons of a particular amino acid per 1,000 codons.

d Total number of codons for the whole genome. 
acid in $P$. sojae and $P$. ramorum $(r=0.76)$. The copy number typically was higher in $P$. sojae than in $P$. ramorum, except for a few cases where there was a significantly higher number of tRNA genes present for $P$. ramorum than $P$. sojae (Fig. 2). The alanine, phenylalanine, and lysine tRNA genes were more numerous in $P$. ramorum than in $P$. sojae. There existed a very weak correlation between the codon usage frequencies in the protein-coding regions and the corresponding tRNA gene frequencies ( $r=0.12$ in $P$. sojae and $r=0.19$ in $P$. ramorum). This is in contrast to the earlier established hypothesis that there is strong correlation between the two (Percudani et al.

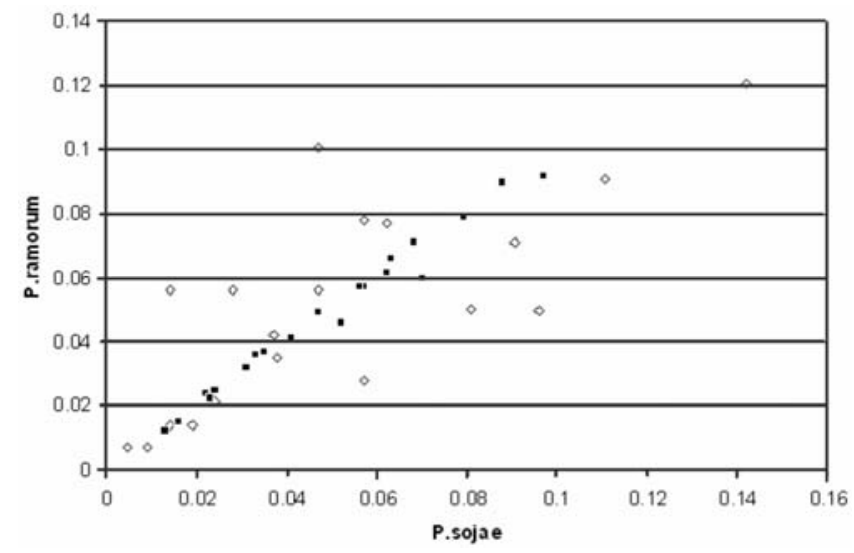

Fig. 1. Amino acid codon usage frequency of Phytophthora sojae versus $P$. ramorum ( $), r=0.99$, and amino acid transfer (t)RNA gene frequency of P. sojae versus $P$. ramorum $(\diamond), \mathrm{r}=0.7$.
1997). Even considering the codon usage frequencies of highly expressed protein-coding genes, the correlation coefficient was even lower $(r=0.09)$ in $P$. sojae. This lack of correlation is expected if there is extensive use of anticodon modification and wobble pairing in matching tRNAs to codons during translation. Consistent with this explanation, the correlation improved significantly if calculated after pooling the tRNA gene numbers for each amino acid type (amino acid tRNA gene frequencies) and pooling the codon usage frequencies for each amino acid (amino acid codon frequencies) (Fig. 3) ( $r=0.53$ and 0.77 in $P$. sojae and $P$. ramorum, respectively). The differences in the correlations between the two species could be due to differences in the transcription rates of the relevant tRNA genes or the loading efficiencies of the relevant amino acyl-tRNA synthetases. In many unicellular (Kanaya et al. 1999; Percudani et al. 1997) as well as multicellular organisms (Duret 2000), tRNA gene copy number serves as a direct indicator of tRNA content in the cell and correlates strongly with the codon usage ( $r=0.82$ in Caenorhabditis elegans and $r=0.82$ in yeast). However, studies are lacking on genomes high in GC content to conclusively prove whether wobbling is more frequent in $\mathrm{GC}$ rich genomes.

\section{Spatial organization and synteny between the tRNA coding genes.}

The tRNA genes were organized in loose clusters of two or three throughout the genome. In a few cases (Gln, Glu, Gly, and Leu in P. sojae and Met, Lys, Glu, and Ala in P. ramorum), they occurred as clusters of more than four. Very little is known about the genomic organization and chromosomal location of tRNA genes in Phytophthora spp. In some eukaryotes, tRNA
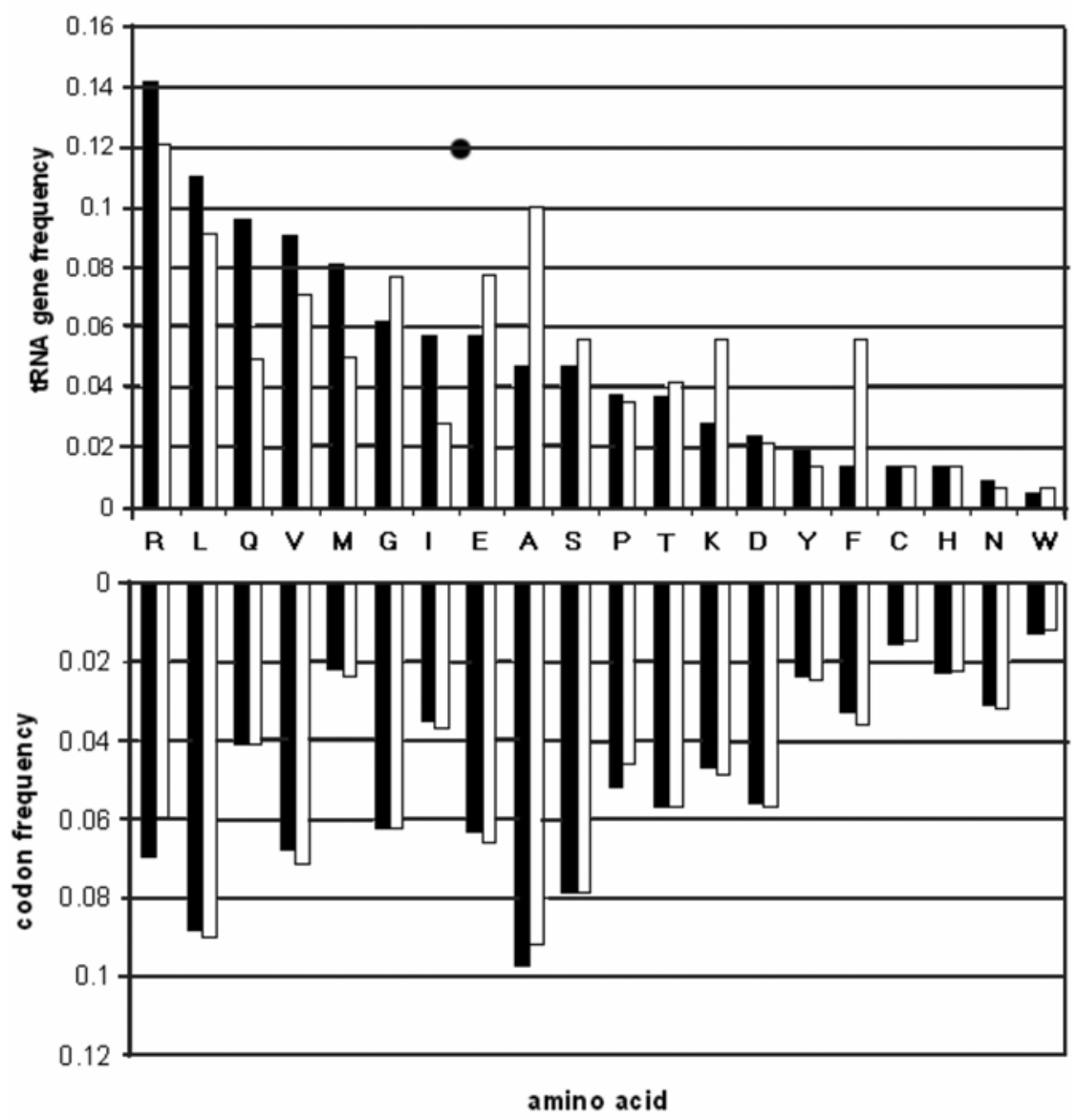

Fig. 2. Transfer (t)RNA gene frequency (upright) and codon usage frequency (inverted) in Phytophthora sojae (ロ) and P. ramorum ( $\square$ ). 
genes are dispersed as single copies (Arnold et al. 1986), whereas others are clustered (Müller et al. 1987; Shortridge et al. 1989). The significance of tRNA gene organization and expression needs to be investigated further.

There has been extensive divergence between the $P$. sojae and $P$. ramorum genomes. Nevertheless, most of the orthologous protein coding genes in the $P$. sojae and $P$. ramorum genomes have syntenic locations (Tyler et al. 2006). By comparison, approximately 59 of the 104 pairs of orthologous tRNA genes have syntenic locations, based on the presence of syntenic orthologous protein-coding genes nearby. In several cases, tRNA gene families in syntenic locations have more members in one species than another. Therefore, 68 and 71 tRNA genes in $P$. sojae and $P$. ramorum, respectively, have locations syntenic with the other species. The reduced synteny of the tRNA genes suggests that whatever evolutionary forces have constrained the protein-coding genes to syntenic locations in the face of extensive genomic diversification have not constrained the tRNA genes so strongly.

\section{Conclusion.}

We have confirmed, at a genomewide level, the strong bias toward $\mathrm{G}$ and $\mathrm{C}$ in the third codon position in Phytophthora spp., and we also have identified a bias toward codons with $\mathrm{G}$ and $\mathrm{C}$ in the first and second positions. We have cataloged all the tRNA genes in $P$. sojae and $P$. ramorum. A consistent absence of tRNA genes with specific anticodons (GNN for amino acids with fourfold redundancy and ANN for amino acids with twofold redundancy) revealed that the two Phytophthora spp. utilize streamlined sets of tRNA genes tuned to the preference for $\mathrm{G}$ and $\mathrm{C}$ in the third codon position. In concert with this observation, a weak correlation between individual codon frequency and isoaccepting tRNA gene frequency indicates that wobble-pairing is used very extensively.

Different tRNA genes often occur in spatial clusters in the two species, suggesting a link between the organization of tRNA genes with their transcription level. On the other hand, the percentage of orthologous tRNA genes located in syntenic regions of the two genomes was less than that for orthologous protein-coding genes (60 compared with 90\%), suggesting a reduced importance of genome position compared with protein-coding genes.

\section{MATERIALS AND METHODS}

The genome sequences of $P$. sojae and $P$. ramorum (Tyler et al. 2006) were obtained through a collaboration with the Department of Energy Joint Genome Institute. For P. sojae, a total of 9,803,525 codons was taken from the entire transcript set (approximately 19,000) and unigenes derived from the expressed sequence tags (ESTs). In the case of $P$. ramorum, the entire transcript dataset $(15,743$ transcripts and $7,496,598$ codons) was used. To calculate the codon usage data, coding sequences were passed through the CUSP program available in the EMBOSS package (Rice et al. 2000).

Table 2. Transfer (t)RNA gene distribution and codon degeneracy in Phytophthora sojae (Ps) and P. ramorum (Pr)

\begin{tabular}{|c|c|c|c|c|c|c|c|c|c|c|c|c|}
\hline \multirow[b]{2}{*}{ Amino acid } & \multirow[b]{2}{*}{ Species $^{c}$} & \multicolumn{4}{|c|}{ No. of functional tRNA genes ${ }^{a}$} & \multicolumn{2}{|c|}{ Anticodon ${ }^{b}$} & \multirow[b]{2}{*}{ Codon specificity $^{d}$} & \multicolumn{2}{|c|}{$\begin{array}{l}\text { Relative tRNA } \\
\text { gene copy no. }\end{array}$} & \multicolumn{2}{|c|}{ Codon usage } \\
\hline & & Ps & & Pr & & tDNA & tRNA & & Ps & Pr & Ps & Pr \\
\hline \multirow[t]{4}{*}{ Ala } & Ala1 & 4 & 10 & 3 & 14 & AGC & IGC & GCU:[GCC ]:GCA & 0.019 & 0.021 & 0.021 & 0.021 \\
\hline & Ala2 & 3 & $\ldots$ & 5 & $\ldots$ & CGC & CGC & GCG & 0.014 & 0.036 & 0.033 & 0.029 \\
\hline & Ala3 & 3 & $\ldots$ & 6 & $\ldots$ & TGC & UGC & GCA:GCG & 0.014 & 0.043 & 0.014 & 0.016 \\
\hline & Ala4 & $\mathbf{0}$ & $\ldots$ & $\mathbf{0}$ & $\ldots$ & GGC & GGC & $\mathrm{GCC}^{*}$ & 0 & $\mathbf{0}$ & 0.034 & 0.027 \\
\hline \multirow[t]{6}{*}{ Arg } & Arg1 & 2 & 30 & 3 & 17 & $\mathrm{ACG}$ & ICG & CGU:[CGC]:CGA & 0.009 & 0.021 & 0.011 & 0.011 \\
\hline & Arg2 & 7 & $\ldots$ & 4 & $\ldots$ & $\mathrm{CCG}$ & $\mathrm{CCG}$ & CGG & 0.033 & 0.028 & 0.011 & 0.009 \\
\hline & Arg3 & 5 & $\ldots$ & 3 & $\ldots$ & CCT & $\mathrm{CCU}$ & AGG & 0.024 & 0.021 & 0.006 & 0.004 \\
\hline & Arg4 & 13 & $\ldots$ & 5 & $\ldots$ & TCG & UCG & CGA:CGG & 0.062 & 0.036 & 0.011 & 0.009 \\
\hline & Arg5 & 3 & $\ldots$ & 2 & $\ldots$ & $\mathrm{TCT}$ & UCU & AGA:AGG & 0.014 & 0.014 & 0.005 & 0.004 \\
\hline & Arg6 & $\mathbf{0}$ & $\ldots$ & $\mathbf{0}$ & $\ldots$ & GCG & GCG & $\mathrm{CGC}^{*}$ & $\mathbf{0}$ & $\mathbf{0}$ & 0.026 & 0.023 \\
\hline \multirow[t]{2}{*}{ Asn } & Asn 1 & 2 & 2 & 1 & 1 & GTT & GUU & AAC:[AAU] & 0.009 & 0.007 & 0.024 & 0.024 \\
\hline & Asn2 & $\mathbf{0}$ & $\ldots$ & $\mathbf{0}$ & $\ldots$ & ATT & AUU & AAU* & 0 & $\mathbf{0}$ & 0.007 & 0.008 \\
\hline \multirow[t]{2}{*}{ Asp } & Asp1 & 5 & 5 & 3 & 3 & GTC & GUC & GAC:[GAU] & 0.024 & 0.021 & 0.041 & 0.040 \\
\hline & Asp2 & $\mathbf{0}$ & $\ldots$ & $\mathbf{0}$ & $\ldots$ & ATC & AUC & GAU* & $\mathbf{0}$ & $\mathbf{0}$ & 0.015 & 0.017 \\
\hline \multirow[t]{2}{*}{ Cys } & Cys1 & $\mathbf{0}$ & $3 * *$ & $\mathbf{0}$ & 2 & $\mathbf{A C A}$ & $\mathrm{ACA}$ & UGU* & $\mathbf{0}$ & $\mathbf{0}$ & 0.004 & 0.004 \\
\hline & Cys 2 & $3 * *$ & $\ldots$ & 2 & $\ldots$ & GCA & GCA & UGC:[UGU] & 0.014 & 0.014 & 0.012 & 0.011 \\
\hline \multirow[t]{2}{*}{ Gln } & Gln 1 & 10 & 20 & 4 & 7 & CTG & CUG & $\mathrm{CAG}$ & 0.048 & 0.028 & 0.029 & 0.029 \\
\hline & $\mathrm{G} \ln 2$ & 10 & $\ldots$ & 3 & $\ldots$ & TTG & UUG & CAA:CAG & 0.048 & 0.021 & 0.012 & 0.012 \\
\hline \multirow[t]{2}{*}{ Glu } & Glu 1 & 5 & 12 & 4 & 11 & CTC & CUC & GAG & 0.024 & 0.028 & 0.047 & 0.046 \\
\hline & Glu2 & 7 & $\ldots$ & 7 & $\ldots$ & TTC & UUC & GAA:GAG & 0.033 & 0.050 & 0.017 & 0.020 \\
\hline \multirow[t]{4}{*}{ Gly } & Gly 1 & 3 & 13 & 1 & 11 & $\mathrm{CCC}$ & $\mathrm{CCC}$ & GGG & 0.014 & 0.007 & 0.010 & 0.009 \\
\hline & Gly2 & 6 & $\ldots$ & 4 & $\ldots$ & $\mathrm{GCC}$ & $\mathrm{GCC}$ & GGC:GGU & 0.029 & 0.028 & 0.029 & 0.028 \\
\hline & Gly3 & 4 & $\ldots$ & 4 & $\ldots$ & TCC & $\mathrm{UCC}$ & GGA:GGG & 0.019 & 0.028 & 0.012 & 0.012 \\
\hline & Gly4 & 0 & $\ldots$ & 2 & $\ldots$ & $\mathrm{ACC}$ & ICC & GGU:GGC:GGA & 0 & 0.014 & 0.011 & 0.013 \\
\hline \multirow[t]{2}{*}{ His } & His 1 & 3 & 3 & 2 & 2 & GTG & GUG & $\mathrm{CAC}:[\mathrm{CAU}]$ & 0.014 & 0.014 & 0.017 & 0.017 \\
\hline & His2 & $\mathbf{0}$ & $\ldots$ & $\mathbf{0}$ & $\ldots$ & ATG & AUG & $\mathrm{CAU}^{*}$ & $\mathbf{0}$ & $\mathbf{0}$ & 0.006 & 0.006 \\
\hline \multirow[t]{3}{*}{ Ile } & Ile1 & 3 & 12 & 1 & 4 & AAT & IAU & AUU:AUA: [AUC] & 0.014 & 0.007 & 0.009 & 0.011 \\
\hline & Ile2 & 9 & $\ldots$ & 3 & $\ldots$ & TAT & UAU & AUA & 0.043 & 0.021 & 0.002 & 0.002 \\
\hline & Ile3 & $\mathbf{0}$ & $\ldots$ & $\mathbf{0}$ & $\ldots$ & GAT & GAU & AUC* & $\mathbf{0}$ & $\mathbf{0}$ & 0.024 & 0.024 \\
\hline \multirow[t]{4}{*}{ Leu } & Leu1 & 3 & 23 & 4 & 13 & AAG & IAG & CUU:[CUC]:CUA & 0.014 & 0.028 & 0.009 & 0.010 \\
\hline & Leu2 & 4 & $\ldots$ & 3 & $\ldots$ & CAA & CAA & UUG & 0.019 & 0.021 & 0.013 & 0.015 \\
\hline & Leu3 & 6 & $\ldots$ & 1 & $\ldots$ & $\mathrm{CAG}$ & $\mathrm{CAG}$ & CUG & 0.029 & 0.007 & 0.036 & 0.036 \\
\hline & & & & & & & & & & \multicolumn{3}{|c|}{ (continued on next page) } \\
\hline
\end{tabular}

\footnotetext{
a tRNA marked with ** are retrieved from the trace archives.

b Anticodons marked in bold are not present in the organism.

c tRNA species marked in bold are not present in the organism.

${ }^{\mathrm{d}}$ Codons in italics (but not in bold) may exhibit wobbling. Anticodons and codons in brackets represent possible wobbling after the $5^{\prime}$ A of tDNA is converted to I in tRNA. Codons marked with an asterisk (*) are potentially provided by other isoaccepting tRNAs by means of wobbling.
} 
The codon usage frequency was calculated by dividing the number of codons by the total number of codon minus stop codons. To establish a relationship between the codon frequency and tRNA gene copy number for highly expressed genes, 40 highly expressed genes were identified using $P$. sojae EST libraries.

The entire genome sequences of $P$. sojae $(78,050,814$ bases, from the $9 \mathrm{X}$ assembly) and $P$. ramorum (54,424,536 bases, from the 7X assembly) were passed through the tRNAscan-SE program (Lowe and Eddy 1997). tRNAscan-SE combines the specificity of the Cove probabilistic RNA prediction package (Eddy and Durbin 1994) with the speed and sensitivity of tRNAscan 1.3 (Fichant and Burks 1991). There were some tRNA types missing from the assemblies: cys-tRNA in $P$. sojae and trp-tRNA in P. ramorum. To check if the missing genes could be found among the unassembled reads, the tRNA sequences from the other species were searched with BLAST against the trace archives. In both cases, reads corresponding to the missing tRNA genes were found and were reassembled manually using DNA Strider. The whole gene list then was updated.

We have used the term "codon usage frequency" to denote the frequency of individual codons as a fraction of the total number of codons predicted in each genome. We have used the term "tRNA gene copy number" to denote the actual number of tRNA genes with an individual anticodon predicted by tRNAscan-SE in each genome and the term "tRNA gene frequency" to indicate the number of tRNA genes with an individual anticodon divided by the total number of tRNA genes in each genome (we have not included the pseudo and nondetermined tRNA types for this). For some analyses, the codon frequencies and tRNA gene frequencies were pooled for each amino acid. In these cases, we have used the terms "amino acid codon frequencies" and "amino acid tRNA gene frequencies."

Correlation coefficients of different groups were calculated and plotted in Microsoft Excel. All the programs were run on a

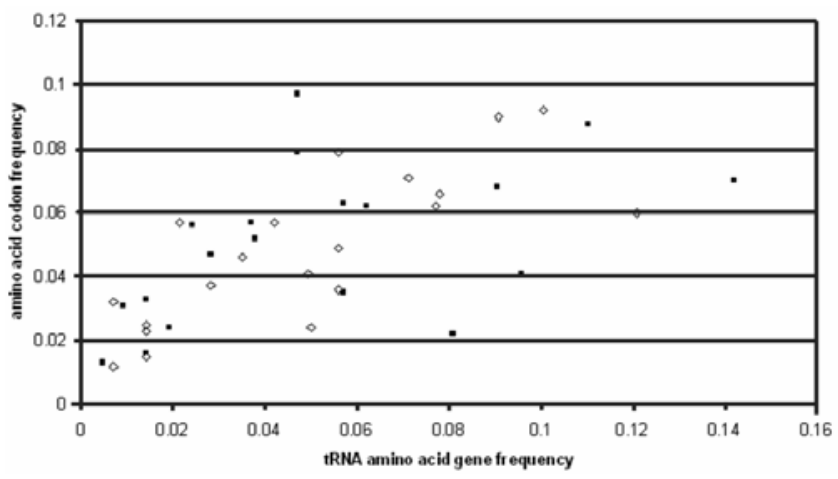

Fig. 3. Amino acid transfer (t)RNA gene frequency versus amino acid codon frequency in Phytophthora sojae (匹), $r=0.533$, and P. ramorum $(\diamond), r=0.77$.

Table 2. (continued from preceding page)

\begin{tabular}{|c|c|c|c|c|c|c|c|c|c|c|c|c|}
\hline \multirow[b]{2}{*}{ Amino acid } & \multirow[b]{2}{*}{ Species $^{\mathrm{c}}$} & \multicolumn{4}{|c|}{ No. of functional tRNA genes ${ }^{a}$} & \multicolumn{2}{|c|}{ Anticodon $^{\text {b }}$} & \multirow[b]{2}{*}{ Codon specificity $^{d}$} & \multicolumn{2}{|c|}{$\begin{array}{c}\text { Relative tRNA } \\
\text { gene copy no. }\end{array}$} & \multicolumn{2}{|c|}{ Codon usage } \\
\hline & & Ps & & Pr & & tDNA & tRNA & & Ps & Pr & Ps & Pr \\
\hline \multirow[t]{3}{*}{ Leu } & Leu4 & 6 & $\ldots$ & 2 & $\ldots$ & TAA & UAA & UUA:UUG & 0.029 & 0.014 & 0.002 & 0.002 \\
\hline & Leu5 & 4 & $\ldots$ & 3 & $\ldots$ & TAG & UAG & CUA:CUG & 0.019 & 0.021 & 0.005 & 0.005 \\
\hline & Leu6 & $\mathbf{0}$ & $\ldots$ & $\mathbf{0}$ & $\ldots$ & GAG & GAG & CUC* & $\mathbf{0}$ & $\mathbf{0}$ & 0.023 & 0.022 \\
\hline \multirow[t]{2}{*}{ Lys } & Lys1 & 4 & 6 & 4 & 8 & CTT & CUU & AAG & 0.019 & 0.028 & 0.040 & 0.039 \\
\hline & Lys2 & 2 & $\ldots$ & 4 & $\ldots$ & TTT & UUU & AAA:AAG & 0.009 & 0.028 & 0.007 & 0.010 \\
\hline Met & Met1 & 17 & 17 & 7 & 7 & CAT & CAU & AUG & 0.081 & 0.050 & 0.022 & 0.024 \\
\hline \multirow[t]{2}{*}{ Phe } & Phe1 & 3 & 3 & 4 & 8 & GAA & GAA & UUC:UUU & 0.014 & 0.028 & 0.026 & 0.027 \\
\hline & Phe2 & 0 & & 4 & & AAA & IAA & UUU:UUC & 0 & 0.028 & 0.007 & 0.009 \\
\hline \multirow[t]{4}{*}{ Pro } & Pro1 & 5 & 8 & 3 & 5 & AGG & IGG & CCU:[CCC]:CCA & 0.024 & 0.021 & 0.009 & 0.009 \\
\hline & Pro2 & 1 & $\ldots$ & 1 & $\ldots$ & CGG & CGG & CCG & 0.005 & 0.007 & 0.021 & 0.018 \\
\hline & Pro3 & 2 & $\ldots$ & 1 & $\ldots$ & TGG & UGG & CCA:CCG & 0.009 & 0.007 & 0.009 & 0.008 \\
\hline & Pro4 & $\mathbf{0}$ & $\ldots$ & $\mathbf{0}$ & $\ldots$ & GGG & GGG & $\mathrm{CCC}^{*}$ & 0 & $\mathbf{0}$ & 0.013 & 0.011 \\
\hline \multirow{6}{*}{ Ser } & Ser1 & 1 & 10 & 2 & 8 & AGA & IGA & UCU:[UCC]:UCG & 0.005 & 0.014 & 0.007 & 0.008 \\
\hline & Ser2 & 4 & $\ldots$ & 2 & $\ldots$ & CGA & CGA & UCG & 0.019 & 0.014 & 0.024 & 0.023 \\
\hline & Ser3 & 2 & $\ldots$ & 0 & $\ldots$ & GCT & GCU & AGC:[AGU] & 0.009 & 0 & 0.021 & 0.019 \\
\hline & Ser4 & 3 & $\ldots$ & 4 & $\ldots$ & TGA & UGA & UCA:UCG & 0.014 & 0.028 & 0.006 & 0.007 \\
\hline & Ser5 & $\mathbf{0}$ & $\ldots$ & $\mathbf{0}$ & $\ldots$ & GGA & GGA & UCC* & $\mathbf{0}$ & $\mathbf{0}$ & 0.013 & 0.013 \\
\hline & Ser6 & $\mathbf{0}$ & $\ldots$ & $\mathbf{0}$ & $\ldots$ & ACT & $\mathbf{A C U}$ & $\mathrm{AGU}^{*}$ & $\mathbf{0}$ & 0 & 0.008 & 0.009 \\
\hline \multirow[t]{4}{*}{ Thr } & Thr1 & 2 & 8 & 2 & 6 & AGT & IGU & ACU:ACA: [ACG] & 0.009 & 0.014 & 0.009 & 0.009 \\
\hline & Thr2 & 2 & $\ldots$ & 0 & $\ldots$ & CGT & CGU & ACC & 0.009 & 0 & 0.015 & 0.014 \\
\hline & Thr3 & 4 & $\ldots$ & 4 & $\ldots$ & TGT & UGU & ACA:ACG & 0.019 & 0.028 & 0.007 & 0.008 \\
\hline & Thr4 & o & $\ldots$ & 0 & $\ldots$ & CGT & CGU & $\mathrm{ACG}^{*}$ & $\mathbf{0}$ & $\mathbf{0}$ & 0.026 & 0.026 \\
\hline \multirow[t]{2}{*}{ Tyr } & Tyr1 & 4 & 4 & 2 & 2 & GTA & GUA & UAC:[UAU] & 0.019 & 0.014 & 0.020 & 0.020 \\
\hline & Tyr2 & $\mathbf{0}$ & $\ldots$ & $\mathbf{0}$ & $\ldots$ & ATA & AUA & UAU* & $\mathbf{0}$ & $\mathbf{0}$ & 0.004 & 0.005 \\
\hline $\operatorname{Trp}$ & Trp1 & 1 & 1 & $1 * *$ & $1 * *$ & $\mathrm{CCA}$ & $\mathrm{CCA}$ & UGG & 0.005 & 0.007 & 0.013 & 0.012 \\
\hline \multirow[t]{4}{*}{ Val } & Val1 & 1 & 18 & 1 & 10 & AAC & IAC & GUU:[GUC]:GUA & 0.005 & 0.007 & 0.009 & 0.010 \\
\hline & Val2 & 8 & $\ldots$ & 6 & $\ldots$ & CAC & $\mathrm{CAC}$ & GUG & 0.038 & 0.043 & 0.035 & 0.037 \\
\hline & Val3 & 9 & $\ldots$ & 3 & $\ldots$ & TAC & UAC & GUA:GUG & 0.043 & 0.021 & 0.004 & 0.005 \\
\hline & Val4 & 0 & $\ldots$ & 0 & $\ldots$ & GAC & GAC & GUC* & 0 & 0 & 0.020 & 0.019 \\
\hline \multirow[t]{9}{*}{ pseudo } & Gly4 & 4 & 16 & 0 & 11 & ACC & $\mathrm{ACC}$ & GGU & $\ldots$ & $\ldots$ & $\ldots$ & $\ldots$ \\
\hline & Trp1 & 7 & $\ldots$ & 0 & $\ldots$ & CCA & CCA & UGG & $\ldots$ & $\ldots$ & $\ldots$ & $\ldots$ \\
\hline & Met1 & 1 & $\ldots$ & 0 & $\ldots$ & CAT & CAU & AUG & $\ldots$ & $\ldots$ & $\ldots$ & $\ldots$ \\
\hline & Pro2 & 1 & $\ldots$ & 0 & $\ldots$ & CGG & CGG & CCG & $\ldots$ & $\ldots$ & $\ldots$ & $\ldots$ \\
\hline & Gly1 & 1 & $\ldots$ & 2 & $\ldots$ & $\mathrm{CCC}$ & $\mathrm{CCC}$ & GGG & $\ldots$ & $\ldots$ & $\ldots$ & $\ldots$ \\
\hline & Lys2 & 2 & $\ldots$ & 1 & $\ldots$ & TTT & UUU & AAA & $\ldots$ & $\ldots$ & $\ldots$ & $\ldots$ \\
\hline & Lys1 & 0 & $\ldots$ & 1 & $\ldots$ & CTT & CUU & AAG & $\ldots$ & $\ldots$ & $\ldots$ & $\ldots$ \\
\hline & Tyr1 & 0 & $\ldots$ & 1 & $\ldots$ & GTA & GUA & UAC & $\ldots$ & $\ldots$ & $\ldots$ & $\ldots$ \\
\hline & ??? & 1 & $\ldots$ & 6 & $\ldots$ & $? ? ?$ & $? ? ?$ & $? ? ?$ & $\ldots$ & $\ldots$ & $\ldots$ & $\ldots$ \\
\hline Undetermined & $? ? ?$ & 14 & 14 & 4 & 4 & $? ? ?$ & $? ? ?$ & $? ? ?$ & $\ldots$ & $\ldots$ & $\ldots$ & $\ldots$ \\
\hline
\end{tabular}


Sun Fire V250, $2 \times 1.28 \mathrm{GHz}$ UltraSPARC IIIi processor machine.

\section{ACKNOWLEDGMENTS}

This work was supported by grants to B. M. Tyler from the National Research Initiative of the United States Department of Agriculture Cooperative State Research, Education and Extension Service, grant number 2002-35600-12747, and from the United States National Science Foundation, grant number MCB-0242131, and by funds from the United States Department of Energy Joint Genome Institute and the Virginia Bioinformatics Institute. We thank M. C. Chibucos for careful editing of the manuscript.

\section{LITERATURE CITED}

Arnold, G. J., Schmutzler, C., Thomann, U., Van Tol, H., and Gross, H. J. 1986. The human tRNAVal gene family: Organization, nucleotide sequences and homologous transcription of three single-copies gene. Gene 44:287-297.

Bulmer, M. 1987. Coevolution of codon usage and transfer RNA abundance. Nature 325(6106):728-730.

D’Onofrio, G., Mouchiroud, D., Aissani, B., Gautier, C., and Bernardi, G. 1991. Correlations between the compositional properties of human genes, codon usage, and amino acid composition of proteins. J. Mol. Evol. 32:504-510.

Duret, L. 2000. tRNA gene number and codon usage in the C. elegans genome are co-adapted for optimal translation of highly expressed genes. Trends Genet. 2000 16(7):287-289.

Eddy, S. R., and Durbin, R. 1994. RNA sequence analysis using covariance models. Nucleic Acids Res. 22:2079-2088.

Eyre-Walker, A. 1996. Synonymous codon bias is related to gene length in Escherichia coli: Selection for translational accuracy? Mol. Biol. Evol. 13:864-872.

Fichant, G. A., and Burks, C. 1991. Identifying potential tRNA genes in genomic DNA sequences. J. Mol. Biol. 220:659-671.

Grantham, R., Gautier, C., Gouy, M., Jacobzone, M., and Mercier, R.1981 Codon catalog usage is a genome strategy modulated for gene expressivity. Nucleic Acid Res. 9:43-74.

Ikemura, T. 1982. Correlation between the abundance of yeast transfer RNAs and the occurrence of the respective codons in protein genes. Differences in synonymous codon choice patterns of yeast and Escherichia coli with reference to the abundance of isoaccepting transfer RNAs. J. Mol. Biol. 158:573-597.

Jiang, R. H. Y., and Govers, F. 2006. Non-neutral GC3 and retroelement codon mimicry in Phytophthora. J. Mol. Evol. 63:458-472.

Kanaya, S., Yamada, Y., Kudo, Y., and Ikemura, T. 1999. Studies of codon usage and tRNA genes of 18 unicellular organisms and quantification of Bacillus subtilis tRNAs: Gene expression level and species-specific diversity of codon usage based on multivariate analysis. Gene 238:143-155.

Knight, R. D., Freeland, S. J., and Landweber, L. F. 2001. A simple model based on mutation and selection explains trends in codon and aminoacid usage and GC composition within and across genomes. Genome Biol. 2(4):1-13

Lobry, J. R., and Gautier, C. 1994. Hydrophobicity, expressivity and aromaticity are the major trends of amino-acid usage in 999 Escherichia coli chromosome-encoded genes. Nucleic Acids Res. 22:3174-3180.

Lowe, T. M., and Eddy, S. R. 1997. tRNAscan-SE: A program for improved detection of transfer RNA genes in genomic sequence. Nucleic Acids Res. 25(5):955-964.

Ma, J., Campbell, A., and Karlin S. 2002. Correlations between Shine-Dalgarno sequences and gene features such as predicted expression levels and operon structures. J Bacteriol. 184:5733-5745.

Moriyama, E. N., and Powell, J. R.1997. Codon usage bias and tRNA abundance in Drosophila. J. Mol. Evol. 45(5):514-23.

Müller, F., Clarkson, S. G., and Galas, D. J. 1987. Sequence of a $3.18 \mathrm{~kb}$ tandem repeat of Xenopus laevis DNA containing 8 tRNA genes. Nucleic Acids Res. 15(17):7191.

Percudani, R., and Ottonello, S. 1999. Selection at the wobble position of codons read by the same tRNA in Saccharomyces cerevisiae. Mol. Biol. Evol. 16(12):1752-1762

Percudani, R., Pavesi, A., and Ottonello, S. 1997. Transfer RNA gene redundancy and translational selection in Saccharomyces cerevisiae. J. Mol. Biol. 268:322-330.

Randall, T. A., Dwyer, R. A., Huitema, E., Beyer, K., Cvitanich, C., Kelkar, H., Fong, A. M., Gates, K., Roberts, S., Yatzkan, E., Gaffney, T., Law, M., Testa, A., Torto-Alalibo, T., Zhang, M., Zheng, L., Mueller, E. Windass, J., Binder, A., Birch, P. R., Gisi, U., Govers, F., Gow, N. A., Mauch, F., van West, P., Waugh, M. E., Yu, J., Boller, T., Kamoun, S., Lam, S. T., and Judelson, H. S. 2005. Large-scale gene discovery in the oomycete Phytophthora infestans reveals likely components of phytopathogenicity shared with true fungi. Mol. Plant-Microbe Interact. 18:229-243.

Rice, P., Longden, I., and Bleasby, A. 2000. EMBOSS: The European molecular biology open software suite. Trends Genet. 16:276-277.

Shortridge, R. D., Johnson, G. D., Craig, L. C., Pirtle, I. L., and Pirtle, R. M. 1989. A human tRNAgene heterocluster encoding threonine, proline and valine tRNAs. Gene 79:309-324.

Tyler, B. M., Tripathy, S., Zhang, X., Dehal, P., Jiang, R., Aerts, A., Arredondo, F., Baxter, L., Bensasson, D., Beynon, J. L., Damasceno, C. M. B., Dickerman, A., Dorrance, A. E., Dou, D., Dubchak, I., Garbelotto, M., Gijzen, M., Gordon, S., Govers, F., Grunwald, N., Huang, W., Ivors, K., Jones, R. W., Kamoun, S., Krampis, K., Lamour, K., Lee, M. K., McDonald, W. H., Medina, M., Meijer, H. J. G., Nordberg, E., Maclean, D. J., Ospina-Giraldo, M. D., Morris, P., Phuntumart, V., Putnam, N., Rash, S., Rose, J. K. C., Sakihama, Y., Salamov, A., Savidor, A., Scheuring, C., Smith, B., Sobral, B. W. S., Terry, A., Torto-Alalibo, T., Win, J., Xu, Z., Zhang, H., Grigoriev, I., Rokhsar, D., and Boore, J. 2006. Phytophthora genome sequences uncover evolutionary origins and mechanisms of pathogenesis. Science. 313:1261-1266.

Wan, X., Xu, D., and Zhou, J. 2003. A new informatics method for measuring synonymous codon usage bias. Pages 1101-1118 in: Intelligent Engineering Systems Through Artificial Neural Networks. ASME Press, New York.

Watkins, N. E., and SantaLucia, J. 2005. Nearest-neighbor thermodynamics of deoxyinosine pairs in DNA duplexes. Nucleic Acids Res. 33(19):6258-6267

Zuckerkandl, E., and Pauling, L. 1965. Molecules as documents of evolutionary history. J. Theor. Biol. 8(2):357-366.

\section{AUTHOR RECOMMENDED INTERNET RESOURCE}

COVE software: www.genetics.wustl.edu/eddy/software 